\title{
Metaphysical energy based sustainable yogic farming for enhanced productivity and farmers' well being: A Review
}

\author{
Sain M., ${ }^{1} \otimes$ Singh A., ${ }^{2}$ Kaur A., ${ }^{3}$ Zalpouri R. ${ }^{4}$
}

Received: 13.06 .2020

Revised: 02.07.2020

Accepted: 09.07.2020

\begin{abstract}
Ancient farming methods with yogic techniques are reported as the zero budget sustainable method for cultivation, seed germination, plant growth, and harvesting. It increases the crop yield resulting in enhanced production and improved soil fertility. The Brahma Kumaris' Raja Yoga Meditation (BKRYM) technique revived by Raja Yoga Education and Research Foundation (headquartered at Mount Abu, Rajasthan, India) is scientifically proven not only for an enhanced quality of farm produce but also for the well-being of farmers who practice this meditation. An initiative was taken in the Indian Finance Budget (July 2019) to propose and introduce Zero Budget Natural Farming (ZBNF), which promotes sustainable yogic agriculture. Scientific Research of India, Indian Council of Agricultural Research (ICAR), and Union Agricultural Ministry are also promoting this concept of yogic farming, but the farmers and researchers are not much aware of this holistic concept, which needs to be acknowledged and adapted to the specific social-cultural settings. BKRYM based yogic agriculture is a unique method of farming which helps in the sustainable development of the agroecosystem. This paper is aimed to explore the various studies, which shows that yogic-farming technique (BKRYM + Organic farming) is much efficient and superior to standard organic farming and chemical-based farming in terms of enhancing seed germination, soil health, plant growth, nutritional values, profitability along with farmers' well being and reducing plant diseases, fungal and slug attacks and germination time.
\end{abstract}

Key Words: Environment conservation, Farmers' well-being, Raja yoga meditation, Sustainable development, Yogic farming

\section{Introduction}

The word yogic farming or yogic agriculture refers to the application of meditation techniques in agricultural and farming practices so that farmers can produce nutritious food by empowering the seeds with the use of positive thoughts. It has been reported that metaphysical energy generated by meditation and pure thoughts creates a positive aura, which could be helpful to enhance water quality (Emoto, 2004), seed germination, healthy crop, vegetable growth (Roney-Dougal and Solfvin, 2003) and well-being of humans (Laurene, 2007). After the green revolution (1960), the use of modern equipment, as well as technologies, was

Author's Address

${ }^{1}$ Department of Agricultural Engineering, Baba Banda Singh

Bahadur Engineering College Fatehgarh Sahib, Punjab, India

${ }^{2}$ Department of Psychiatric Nursing State Institute of Nursing and Paramedical Sciences Badal, Punjab, India,

${ }^{3}$ Department of Livestock Products Technology, College of Veterinary Science, GADVASU, Ludhiana, Punjab, India

${ }^{4}$ Department of Processing and Food Engineering Punjab

Agricultural University Ludhiana, Punjab, India

E-mail.: mukulsain95@gmail.com introduced in India for farming. Technologies have played an important role in food production and fulfilling growing population demands, but the excessive chemical fertilisers and pesticide usage have increased agricultural production at the cost of natural resources, soil health that triggered a global alarm. It makes the researchers search for biointensive and sustainable agriculture techniques that can help increasing productivity in an improved manner such that the obtained product remains free from destructive chemical fertilisers and pesticides. India has always been a hub for spiritual healings and the use of spiritual powers for revolutionary benefits. A few experimental studies are conducted on ancient Vedic techniques for farming worldwide. Countries like Greece, Italy, South Africa, and many others are doing researches on yogic techniques in farming (Girme et al., 2019), which are being practiced in India from ancient times. BKRYM technique is one of the revived methods, which is being adopted worldwide because of scientific evidence. Studies have proven that ancient Vedic methods are based on 
agroecology and very effective for increasing crop production, seed vigour, crop yields, and soil quality with minimal input cost (Kumari et al., 2012). The findings and holistic knowledge of Vedas are proven true in every aspect.

Researchers have also concluded that human beings are electromagnetic beings and "what we think, it radiates in the world around us" (Lipton, 2012). The law of attraction is a substantial philosophy that deals with the turning of good intentions into positive actions. In this practice, simple exercises like filling your words and thoughts with positivity, exactly with what we want, and then let it flow in the universe (Anonymous, 2020a). These positive thought based practices are found thriving in healthy farming as well as the overall well-being of humans. One of the metaphysical energy-based meditation techniques have been proposed by 'Rural development wing raja yoga education and research foundation', a branch of the Brahma kumaris ishwariya vishwa vidhyalaya, Mount Abu, Rajasthan, India (Girme et al., 2019), which explains the effect of positive thoughts on the growth of grains, plants, and other food products. It helps the farmers in producing highly nutritious food at minimum cost. Yogic Agriculture is one of the cultivation practices, which improves the ecosystem of agriculture by attaining a powerful and elevated metaphysical state through Raja yoga meditation along with eradicating the use of chemical pesticides and harmful synthetic fertilisers (Ndiritu, 2015). It helps in understanding different elements of farming, which results in the development of self-esteem, increased productivity, improved soil health, reduction of frequency of farmers' suicides, and family violence (Ramsay, 2012). Along with improved farming, the Brahma Kumaris' Raja Yoga Meditation (BKRYM) technique helps in the overall well-being of humans who perform this meditation as shown in fig. 1. This energy-based healing technique channelizes spiritual energy towards any person/patient to bring positive and successful health results (Wayne and Crawford, 2003).

Raja yoga meditation works in every stage of farming from cultivating land to post-harvesting. It also helps in appropriately channelling the metaphysical energy with the power of meditation based on positive spiritual thoughts (Anonymous, 2010) and Sankalpa, which means superior thoughts work under the law of attraction in which pre-set pre-defined act is performed, and pre-set goals are achieved (Anonymous, 2020b). In India, an initiative was taken in the Finance budget (July 2019) proposing and introducing zero budget natural farming (ZBNF) (Anonymous, 2019). The primary aim behind this was to make farming affordable, decrease the overall cost, and also to provide hygienic and healthy agricultural products to the people. Scientific Research of India, ICAR, and Union agricultural ministry is also promoting the concept of Brahma Kumaris' yogic agriculture technique incorporating organic farming (Girme et al., 2019).

\section{Effects of metaphysical energy based BKRYM on crops}

i) Enhanced seed germination, vigour, quality, and growth along with reduced germination time: All the living organisms, including plants, make responses to human intentions (Backster 2003). Positive thoughts based BKRYM technique is experimented in the past few years to increase the quality of seed for better germination and seedling vigour that ultimately enhances the productivity of crops. A study was performed at the Department of Agronomy, G.B. Pant University of Agriculture and Technology, Uttarakhand, India (2012-2013) to analyze the effects of energy treatments, i.e. effects of metaphysical energy through BKRYM practice on seed germination, seed quality, and seedling vigour of chickpea. It was found that in the past recent years, the magnetic field was widely used for safe and low-cost seed germination and to enhance seedling vigour (Tahir and Karim, 2010; Grish et al., 2011). Based on this fact, Rashmi et al. (2014) studied the effects of both physical energy (static magnetic fields) and metaphysical energy (positive thought based BKRYM) on seed germination and seedling vigour of chickpea. In this experiment, chickpea seeds were treated with physical energy by exposing them to static magnetic fields of 100 250 milliTesla (mT) for 1 to 4 hour (h) duration. Also, a trained Raja Yogi from Raja Yoga Education and Research; Mount Abu treated the samples with BKRYM in order to supply metaphysical energy. All experimental and control samples were placed under similar conditions, and it was concluded that positive thought based 
meditation enhanced the vigour parameters and growth of the seedlings. Also, the chickpea seeds exposed to physical energy through the stationary magnetic field below $250 \mathrm{mT}$ intensity for one hour. and metaphysical treatment through positive thought based Raja Yoga Meditation for 2-4 h, improved germination rate as well as seedling vigour of poor quality chickpea seeds. The biochemical properties of seeds were also improved in samples treated with Raja yoga meditation. Also, the mean root length was high in the experimental samples as compared to the control group (Rashmi et al., 2014). The time taken for seed germination can be reduced up to one week by using yogic farming based on BKRYM technique (Ramsay, 2012).

ii) Improved soil characteristics: The effects of Raja yoga meditation were also reported on wheat and groundnuts when similar meditation practice (BKRYM) was performed in Karnal, Haryana, and Dantiwada, Gujarat. In this three years-long experiment, it was found that there was better plant moisture, enhanced soil quality, and organic matter because of metaphysical energy produced by Raja Yoga Meditation (Pandey et al., 2015). These encouraging results of experimental samples have proven the power of metaphysical energy and BKRYM.

iii) Channelising the irrigation water: Some studies revealed that water could reflect the environment at the molecular level (Sharp, 2014). This study concluded that positive metaphysical energy also channelizes the water, which is a basic component of seed germination. Also, water is present inside the seed, soil, and most of the part of the earth is water, ultimately positive vibrations in water lead to an increase in seed germination, seedling growth, and seedling vigour index. Also, it was noted that vibration energies showed positive effects on leguminous crops. Another research study was performed for analysing the effect of meditation on quality of wheat and green peas, and it was concluded that when water treated with meditation was supplied to wheat and green peas, there were visible effects on growth and germination rate of wheat and green peas (Haid and Huprikar, 2001). iv) Reduction in plant diseases, fungal and slug attacks: Roney-Dougal and Solfvin (2003) concluded that healing energy was tremendously effective for the lettuce field. Table 1 shows the increased lettuce yield percentage (\%) and a decrease in fungal attack and diseases when the field was treated with the BKRYM technique by performing meditation in the field by a trained Raja yogi. It was found that there was a $10 \%$ increment in the total crop production, due to which healing technique was found useful for commercial farming.

Table 1. Power of positive thoughts in decreasing pests and plants' diseases.

\begin{tabular}{|l|l|l|l|}
\hline $\begin{array}{l}\text { Name of } \\
\text { crop }\end{array}$ & $\begin{array}{l}\text { \% } \\
\text { Increase } \\
\text { in yield }\end{array}$ & $\begin{array}{l}\text { \%Decrease in } \\
\text { pests } \\
\text { disease }\end{array}$ & Reference \\
\hline $\begin{array}{l}\text { Lettuce- } \\
\text { field }\end{array}$ & $23 \%$ & $\begin{array}{l}10 \% \text { fungal } \\
\text { attack } \\
5 \% \text { slug attack }\end{array}$ & $\begin{array}{l}\text { Roney-Dougal } \\
\text { and Solfvin } \\
(2003)\end{array}$ \\
\hline
\end{tabular}

v) Enhanced nutrition: Along with enhancing seed germination, seedling vigour, productivity, yield, and; keeping the crops and plants safe from diseases, fungal, and slug attack, BKRYM enhances the nutrition of produce. Table 2 shows the nutrition enhancement in tomatoes grown with the meditation technique (RERF, 2009). Also, Ramsay (2012) reported a study conducted in Kolhapur, Maharashtra, India, in which vitamin C and energy content in tomatoes grown with Yogic technique was found much higher than that of tomatoes grown with the chemical process as referred to Fig. 2.

Table 2. The effect of meditation on nutritional value of tomatoes.

\begin{tabular}{|c|c|c|}
\hline Nutrients & $\begin{array}{c}\text { \% Enhanced } \\
\text { nutrition }\end{array}$ & References \\
\hline Fat & 45 & $\begin{array}{l}\text { RERF, 2009; } \\
\text { http://yogickheti } \\
\text {.com/articles.ht } \\
\text { ml }\end{array}$ \\
\cline { 1 - 2 } Protein & 52 & \\
\cline { 1 - 2 } Carbohydrate & 36 & \\
\cline { 1 - 2 } Energy value & 41 & \\
\cline { 1 - 2 } Vitamin C & 146 & \\
\hline
\end{tabular}


vi) High profitability: Studies show that BKRYM based Yogic farming reduces the total production cost and increases profitability. Ramsay (2012) reported that local farmers using Yogic technique saved USD 330\$ per acre land as compared to standard chemical farming methods.
Effects of raja yoga meditation on the well-being of farmers

It has been proven that Raja yoga meditation is not only effective for soil, water, crops, and vegetables but it also works for the well-being of humans who do this meditation (Wayne and Crawford, 2003).

\section{LEVEL OF WELLBEING STATUS}

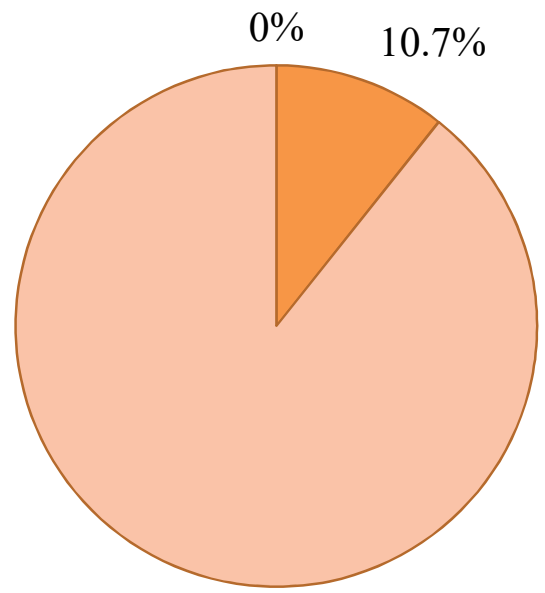

Low well being (50124)

$\square$ High well being (176-250)

$89.3 \%$

Fig 1. Pie diagram showing frequency and percentage of well-being status of individuals performing Rajyoga meditation (adapted from Singh et al., 2019a).

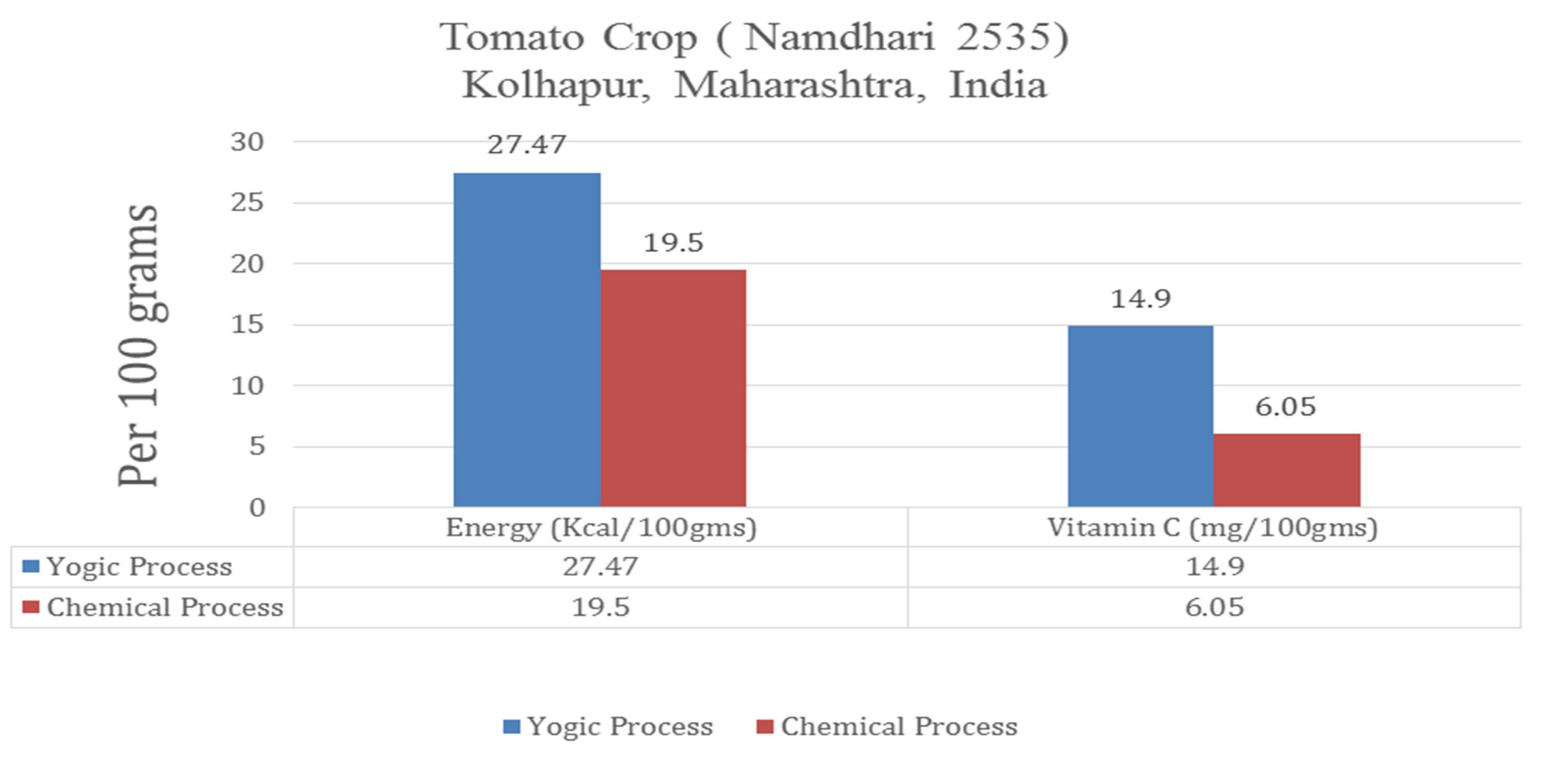

Fig 2. Graph indicating enhanced energy and vitamin ' $C$ ' level in tomato crop treated with BKRYM (adapted from Ramsay, 2012). 
BKRYM helps in relaxing and clearing the mind to rediscover and reconnect with the original supreme power. Practicing Raja yoga meditation helps in enhancing the well-being, socioeconomic status, physical, and the mental health of the farmers eradicating the farmers' suicides (Ramsay, 2012). An exploratory study was conducted in Punjab to evaluate the outcomes of Raja yoga meditation on the well-being status of people performing this meditation (Fig.1). Singh et al. (2019a) studied this method using a multiphase mixed sampling technique. From 150 individual findings, data revealed that person practicing Raja yoga meditation had a high level of well-being with a mean score of 203.13 (Singh, 2018). Raja yoga meditation technique was also found effective for individuals who were addicted to alcohol and other drugs (Singh et al., 2019b). Also, it was found that crops grown with BKRYM practices were full of positive vibrations and healing energy, which would result in the well-being of consumers.

\section{Conclusion}

BKRYM Meditation is widely accepted as a beneficial health and farming practice, which is advantageous as it is largely non-profit driven, and resource-usage free as per a sustainable point of view. With no carbon footprint, it is probably the only technology for sustainable development. In combination with organic ingredients, adopting meditation-based farming is found tremendously beneficial in terms of product quality as well as cost. It has an enormous potential in eradicating the global food crisis and is therefore recommended.

\section{Conflict of interests}

There was no conflict of interest among all the authors. The manuscript has been prepared with the suggestions of all the authors.

\section{References}

Anonymous, 2010. Perpetual yogik kheti. Rural Development Wing. Rajyoga education and research foundations PPBKIVV. Mount Abu, 64.

Anonymous, 2019. https://economictimes.indiatimes.com/ news/economy/agriculture/budget-2019-zero-budgetfarming-has-few-takers-in-the-state-where-itoriginated/articleshow/70089472.cms. (Accessed on May $25,2020)$.
Anonymous, 2020a. http://www.Law of attraction com. (Accessed April 26, 2020).

Anonymous, 2020b. https://www.yogickheti.org/projectdetails.html. (Accessed April 27, 2020).

Backster, C. 2003. Primary perception: Biocommunication with plants, living foods, and human cells. White Rose Millennium Press.

Emoto, M. 2004. Healing with water. Journal of Alternative and Complementary Medicine. 10(1): 19-21.

Girme, A., Deshpande, B. and Dubey, R., 2019. Revolutionary Yogic Agriculture. International Journal of Recent Technology and Engineering. 8(3): 4514-4517.

Grish K., Yadav, S. K., Lal, S. K. and Nagarajan, S. 2011. Static magnetic field treatment enhances seed performance in cotton (Gossypium hirsutum L.). Seed Research 39(2): 124-129.

Haid, M. and Huprikar, S. 2001. Modulation of germination and growth of plants by meditation. The American Journal of Chinese Medicine, 29(3-4): 393-401.

Kumari, N., Babalad, H. P. and Basarkar, P. W. 2012. Effect of homa organic practices on soyabean crop. Organic Farming Newsletter, 8(1): 3-10.

Laurene, D. C. 2007. The effect of intentional thought in close proximity or at a distance: Demonstrating the relation between mind and matter on seed germination. Dissertation submitted to the faculty of holos university Graduate seminary. Missouri, USA, in partial fulfillment of the requirement for the degree of $\mathrm{PhD}$.

Lipton, B. 2012. Quantum physics: spirituality and your life experiences. In: The biology of Belief. (www.abundance-and-happiness.com/quantum-physics. $\underline{\mathrm{html}}$ ).

Ndiritu, J. 2015. Applying acoustic frequency and meditation techniques to improve crop production-a review. 10.13140/RG.2.1.3385.2646. pp: 1-10

Pandey, S. T., Verma, O., Kewalanand, D. S., Gillz, S., Patel, J. C., Pate, G. N., Patel, D. M., Patel, B. T., Pate, B. B., Patel, D. S. and Patel, I. S. 2015. Yogic Farming through Brahma Kumaris Raja Yoga Meditation: An Ancient Technique for Enhancing Crop Performance. Asian Agri-History, 19(2): 105-122.

Ramsay, T. 2012. Yogic agriculture reaping rewards in India. Rio Plus Business magazine, June, 2012, 118-119. http://rioplus.org/rio20-business-focus-yogic-farmingreaping-rewards-in-India.

RERF (Rural Development Wing, Rajyoga Education and Research Foundation and Prajapita Brahma Kumaris Ishwariya Vishwa Vidhyalaya), 2009. Perpetual Yogic 


\section{Sain et al.}

Agriculture (Shashwat Yogic Kheti). A Novel Step towards a New Era. Omshanti Press,India pp : 1-56

Rashmi, S., Pandey, S. T., Omvati, V., Neha, J., Srivastava, R. C. and Guru, S. K. 2014. Effect of physical and metaphysical energy on germination and seedling vigour of chick pea. International Journal of Basic \& Applied Agricultural Research, 12(3): 339-346.

Roney-Dougal, S. M. and Solfvin, J. 2003. Field study of an enhancement effect on lettuce seeds: a replication study Journal of Parapsychology, 67(2): 279-297.

Sharp, S. 2014. Miraculous messages from water: how water reflects our consciousness. (www.wellnessgoods.com)

Singh, A. 2018. An exploratory study to evaluate the outcome of Rajyoga meditation on the well-being status of individuals attending selected Rajyoga meditation centers of Punjab. M.Sc. Thesis submitted to the faculty of State Institute of Nursing and Paramedical Sciences, Badal, Punjab, India, in partial fulfillment for the requirement for the degree of M.Sc.
Singh, A., Sharma, S. B., Kaur, A., Kumari, A., Rani, A. B., Saini, D. and Kaur, G. 2019b. Effectiveness of "Rajyoga meditation" for holistic healing in Addicted patients: A Quasi- experimental study. International Journal of Advanced Research and Review, 4(11): 28-36.

Singh, A., Tak, G. and Sharma, S. B. 2019a. Rajyoga meditation and well-being status: an exploratory study. International Journal of Current Research, 11(1): 64-67. https://doi.org/10.2491/ijcr.33881.01.2019.

Tahir, N. A. R. and Karim, H. F. H. 2010. Impact of magnetic application on the parameters related to growth of chickpea (Cicer arietinum L.). Jordan Journal of Biological Sciences, 3: 175-184.

Wayne B. J. and Crawford, C. C. 2003. Science and Spiritual Healing: a critical Review of spiritual healing, "energy" medicine, and intentionality. Alternative Therapies, Health and Medicine, 9(2): 56-61. 